\title{
Pragmatism, Ontology, and Philosophy of the Social Sciences in Practice
}

Philosophy of the Social Sciences 2017, Vol. 47(I) 3-27

(C) The Author(s) 2016

Reprints and permissions: sagepub.com/journalsPermissions.nav DOI: I0.II77/0048393|I6654869

pos.sagepub.com

(S)SAGE

\section{Simon Lohse'}

\begin{abstract}
In this article, I will discuss two prominent views on the relevance and irrelevance of ontological investigations for the social sciences, namely, ontological foundationalism and anti-ontological pragmatism. I will argue that both views are unsatisfactory. The subsequent part of the article will introduce an alternative role for ontological projects in the philosophy of the social sciences that fares better in this respect by paying attention to the ontological assumptions of actual social scientific theories, models, and related explanatory practices. I will illustrate and support this alternative through discussion of three concrete cases.
\end{abstract}

\section{Keywords}

social ontology, explanation, philosophy of science in practice, pragmatism, ontological foundationalism

\section{Introduction}

This article aims to contribute to the debate revolving around the relevance of ontological projects in the philosophy of the social sciences (POSS). More precisely, the article is an attempt to respond to those neopragmatist

Received 22 December 2015

'Leibniz Universität Hannover, Hannover, Germany

\section{Corresponding Author:}

Simon Lohse, Centre for Ethics and Law in the Life Sciences, Institute of Philosophy, Leibniz Universität Hannover, Am Klagesmarkt 14-17, 30159 Hannover, Germany.

Email: lohse@ww.uni-hannover.de 
philosophers who contest the usefulness of ontological investigations for the social sciences tout court and, hence, propose that we should stop pursuing ontological projects in POSS in favor of epistemological and methodological investigations (Kivinen and Piiroinen 2006, 2007; Tsilipakos 2012; Van Bouwel and Weber 2008). ${ }^{1}$ My goal here is to defend the view that ontological investigations of a certain kind can indeed be relevant for the social sciences.

Note that a concern for the relevance of ontological projects in POSS for the social sciences cannot be taken for granted. The reason for this is that there are several different aims an ontologically minded philosopher of the social sciences (or any of the special sciences) might have. Some philosophers of the social sciences might primarily be concerned with developing their own theory of social reality. As part of such an enterprise, they might be interested in the social sciences only to serve as contrast or springboard for developing an independent social theory that is supposed to make sense of social reality. Other philosophers might be aiming at naturalizing metaphysics, that is, pursuing some kind of scientifically informed metaphysics that attempts to paint an accurate overall picture of the world - in our case, the social world - that is compatible with, constrained by, or based on the current state of the art of our best social sciences. This seems to be a sensible project in the philosophy of the natural sciences (Ladyman et al. 2007), and it would be a legitimate - though, at the current state of the social sciences, hardly achievable - project in POSS. Neither of these two projects is meant, at least not in a straightforward sense, to be relevant for the social sciences in the first place. Projects such as these, therefore, do not fall within the scope of this article. ${ }^{2}$ My aim is rather to develop some meta-ontological thoughts, which focus on ontological investigations in POSS that are indeed meant to be useful for the social sciences. I attempt to flesh out a position

\footnotetext{
${ }^{1}$ There are other neopragmatist philosophies of the social sciences, which I do not address in this article, for example, Baert (2005).

${ }^{2}$ This limitation of the article should not be read as a dismissal of philosophies of the social sciences that do not aim at being relevant or useful for the social sciences in a direct sense. In fact, I do not believe that the legitimacy of any philosophy of a special science is determined by its relevance for the respective special science. It seems to be perfectly reasonable for a project of any philosophy of the special sciences to try to understand a certain special science and make sense of the picture of the world it provides from a philosophical point of view - without the motivation to criticize or advance the respective special science. The critique and advancement of science, though an important enterprise, is just one of the reasonable aims a philosopher of a special science can have.
} 
that is, I believe, latent in many naturalist approaches to POSS and that implies a reorientation of ontological projects in POSS. In a nutshell, I want to show that the practice turn in philosophy of science would also be fruitful for doing ontology in POSS.

The structure of this article is as follows. After some clarifying remarks on my terminology (Section 2), I will discuss two prominent views on the relevance and irrelevance of ontological investigations for the social sciences, namely, ontological foundationalism and anti-ontological pragmatism (Section 3). I will argue that both views are unsatisfactory. The subsequent Section 4 of the article will introduce an alternative role for ontological projects in POSS that fares better in this respect by paying attention to the ontological assumptions of actual social scientific theories, models, and related explanatory practices. I will illustrate and support this alternative through discussion of three concrete cases. In the conclusion (Section 5), I will wrap up the main points of my discussion.

\section{Terminological Clarifications}

Before I begin with the discussion, there are two clarifying remarks about my terminology in order. The first remark concerns my use of the term social sciences. For the purpose of this article, I primarily want to subsume sociology, cultural anthropology, and political science under this label. My intention here is not to say that economics is not really a social science (I think it is). However, there are significant differences between economics and the other social sciences, which necessitate this separation. Here are three main differences. (a) Economics has a leading, although not completely uncontested (see Davis 2006), paradigm, ${ }^{3}$ namely, the neoclassical synthesis, whereas the other social sciences are extremely multiparadigmatic. (b) Economics features a higher degree of formalization and mathematization than the other social sciences (Debreu 1991). (c) Large parts of economics place a huge role on predictions of social — especially economic — events and processes. Friedman ([1953] 2008, 148) even called it the ultimate goal of economics as a positive science (see, however, Reiss 2013, 8ff., for a broader perspective). The other social sciences, in contrast, are far less interested in

\footnotetext{
${ }^{3}$ I use the term paradigm not in Kuhn's but in a broader sense, roughly meaning "explanatory framework" (e.g., Analytical Marxism, Practice Theory), as many paradigms in the social sciences do not seem to exhibit one of the key features of Kuhnian paradigms, namely, to be exemplary solutions to prominent research problems (Hoyningen-Huene and Lohse 2015, 136).
} 
predictions. They aim to a greater degree at explaining and thereby understanding social phenomena. These and related aspects also seem to be the reason for the existence of a distinctive disciplinary identity in economics and the existence of a separate subphilosophy of economics with its own journals (e.g., Economics \& Philosophy), discourses (Hausman 2008), and postgraduate degrees.

The second remark concerns my use of the phrase ontological investigations (I will also use the terms ontological reasoning or doing ontology, which I take to be synonyms in this context). What do I mean by these terms in the context of the social sciences? I hereby mean thinking or reflecting about questions such as the following:

- What is the ultimate furniture of the social world?

- What are the general properties of social phenomena such as organizations or religions? (e.g., causal efficacy)

- What is their mode of existence? (e.g., Are they real and autonomous in some sense, real and ontologically dependent in some sense, or mere fictions?)

- How are facts about "the social" (e.g., universities) and "the individual" (e.g., individual actions) related?

- How is social reality, in general, related to other aspects of reality?

- Are there layers or levels of social reality-say micro-, meso-, and macro levels - and, if so, how are they related?

In short, I subsume both investigations concerned with the question of what there is ("furniture questions") in the social world and projects aiming at the nature of social entities and relations between different kinds of entities under this label. I take it that this broad understanding of ontology is fairly uncontroversial within POSS (see Epstein 2015a). My aim in this article, however, is not to answer any of those questions but to look at two opposed assessments of the relevance of these questions for the social sciences and to present an argument that may further a reorientation, that is, a more fruitful way of engaging with questions like these in POSS. In the course of this, I will frequently refer to the individualism/holism disputes for illustrative purposes, as they are central to many debates in social ontology (see Zahle and Collin 2014).

\section{Two Prominent Views}

There are two prominent views on the relevance of doing ontology in contemporary POSS. First, there are those who think that ontological investigations play a central role for the social sciences as they are the foundation for 
the explanation of social phenomena, social regularities, and the effects that social phenomena have on individual behavior. I call this view ontological foundationalism. Advocates of ontological foundationalism often argue that ontological issues in the social sciences have not received enough attention in the past and that we therefore need more serious thinking about social ontology to arrive at a solid foundation for the social sciences. The second camp thinks that ontological investigations are irrelevant or fruitless for explanations in the social sciences: I call this view anti-ontological pragmatism. Advocates of anti-ontological pragmatism typically argue that ontological issues in the social sciences have received too much attention in the past and that we need less (or no) thinking about social ontology in POSS. Instead, philosophers of the social sciences should focus their efforts more exclusively on epistemological and methodological work.

\section{I. Ontological Foundationalism: "Ontology First!"}

Who endorses ontological foundationalism? Naturally, some philosophers in social ontology have argued explicitly for the importance of doing ontology for the social sciences. In an article from 2008, Searle (2008, 443f.), ${ }^{4}$ one of the godfathers of modern social ontology, says,

I believe that where the social sciences are concerned, social ontology is prior to methodology and theory. It is prior in the sense that unless you have a clear conception of the nature of the phenomena you are investigating, you are unlikely to develop the right methodology and the right theoretical apparatus for conducting the investigation. (emphasis added)

Searle is not very explicit about the exact relationship between ontology and methodology/the development of theoretical tools for the investigation of social reality here (or anywhere else). In a closing passage in Making the Social World, he even admits that he does not really know what the implications of his theory for research in the social sciences are (Searle 2010, 200). It seems to be clear, however, that Searle's $(2010,201)$ general outlook is that

${ }^{4}$ Objection: "Why Searle? Is he really a philosopher of the social sciences? Searle does not engage with the social scientific literature, and he is barely cited in sociological discourse." I agree, but I think he should be included nevertheless. For one, he is widely recognized as an important participant in the ontological discourse in philosophy of the social sciences (Guala 2007; Mantzavinos 2009). In addition, Searle (1995, 2010) explicitly aims, among other things, at improving the social sciences by providing a general picture of the ontological foundations of social reality. 
the development of theories and explanatory tools in the social sciences somehow should depend on ontological foundations as "the whole investigation gets a greater depth if one is acutely conscious of the ontology of the phenomena being investigated."

Still, these statements by Searle are quite abstract. Looking at the individualism/holism debate in POSS, matters become more concrete. Consider Keith Sawyer's writings in POSS. Sawyer $(2002,2003,2005)$ aims at developing a position he calls "non-reductive individualism," by analogy to one of the mainstream positions in philosophy of mind: nonreductive materialism. He draws from well-known concepts in the philosophy of mind debate, above all supervenience and multiple realizability, to argue for a middle-ground position in POSS between strong holism and individualism. This position is supposed "to provide a philosophical argument to ground collectivist macrosociology" (Sawyer 2002, 539). At first glance, Sawyer $(2002,538)$ does not seem to be an ontological foundationalist at all as he aims to avoid "the logical error of making ontological arguments in support of methodological claims." If you look at his philosophical strategy, it becomes clear, however, that the core of his argument actually presupposes that we, first, need to get the ontology right and can then draw conclusions from this concerning social explanations. As a matter of fact, Sawyer seems to follow Durkheim ([1895] 1964) in thinking that it is necessary to show that certain social phenomena really have emergent causal powers to argue for the indispensability of holist explanations in sociology. Apparently, many philosophers of the social sciences arguing for some kind of holism think that a variation of Sawyer's "ontological argument" is plausible. The main idea of this argument is that holist explanations are only informative and legitimate if it can be shown that social entities have real causal powers, or some kind of ontological status sui generis, despite the fact that they supervene on individuals and their interactions (see the articles by Van Bouwel 2004 and Zahle 2003 for details).

Critical realists in the tradition of Roy Bhaskar defending an emergentist ontology (such as Margaret Archer and Dave Elder-Vass) to argue against methodological individualism seem to have similar things in mind. In his book The Causal Power of Social Structures, Elder-Vass $(2010,8)$ develops a position that

recognises the contributions of both social structure and human agency to explaining social events, and also the complexity of the interactions between them. It is therefore distinct from methodological individualist positions, which deny causal effectiveness to social structure ...

According to this theory, social groups, in Elder-Vass' terminology "norm circles," and organizations can exert genuine causal powers, most notably by 
producing and endorsing social norms, which only then become a part of social reality or "culture." This relational theory of social emergence is (arguably) in contrast to an individualist ontology and is also used to show the deficiency of individualist explanations in the social sciences. Once again, ontological arguments are considered to be foundational for explanatory practices in the social sciences, in this instance, as an ontological ground for rejecting methodological individualist explanations (Elder-Vass 2010, 196).

On the other end of the individualism/holism spectrum, we have, for example, proponents of Analytical Sociology who endorse ontological foundationalism in a straightforward way. Pierre Demeulenaere $(2011,4)$ expresses this view in this way: "Social life exists only by virtue of actors who live it." From this ontological premise follows immediately a methodological postulate. "Consequently, a social fact of any kind must be explained by direct reference to the actions of its constituents [individual actors]" (emphasis added). Needless to say, John Watkins $(1952,1957)$ and Daniel Little $(1998,10)$ express similar arguments: the requirement of individualist explanations follows directly — and naturally - from ontological individualism.

At first glance, Daniel Little's most recent position in this debate seems not entirely clear. ${ }^{5}$ On one hand, he argues that a plurality of approaches in the social is needed and legitimate. On the other hand, he develops his own kind of social ontology and says,

I believe that the social sciences need to be framed out of consideration of a better understanding of the nature of the social-a better social ontology. (Little 2009, 174, emphasis in the original)

Little (2009) even makes methodological recommendations regarding the best kinds of explanations - namely, causal mechanistic explanationsthat are at least partly motivated by his "localist" social ontology. Does he also exclude certain types of explanations on ontological grounds? I think he does. I believe the most plausible interpretation of his position is that Little $(2014,57)$ endorses a plurality of explanatory approaches in the social sciences - albeit constrained by his (more or less) individualist social ontology:

If our social ontology maintains that complex social processes and assemblages take shape out of the actions and thoughts of individuals, then it is logical that we need to develop a theory of the actor. This does not imply that our

${ }^{5}$ Most recently, Little has moved away from his earlier strong microfoundationalist position in recent articles. 
explanations always need to proceed from individual level to social level; sometimes this is an appropriate explanatory strategy and sometimes it is not. But even in circumstances where our explanations include hypotheses that refer to social entities, we still need to have some idea of the kinds of actions and interactions [of individuals] that establish the properties of those entities. (emphasis added)

In my view, this makes him a mild ontological foundationalist aiming to reject what could be called "pure holist explanations," that is, explanations referring to social entities without any kind of in-principle microfoundations of these entities, for ontological reasons.

Note that the basic rationale in both the individualist and the holist arguments is the same: ontology comes first and has important consequences for the social sciences, particularly for the choice of individualist or holist explanations. If (for example) entities on the macro level (whatever this is exactly) are only composed of individuals, their properties, and relations, and if (say) strong social emergentism does not hold, we do not need holist explanations and purely holist explanations are not gold standard, respectively. If not, holist explanations are indispensable or gold standard. The main difference is that, in many cases, the individualist camp assumes the individualist ontology's truth as self-evident or trivial (Watkins 1952) - it only needs to be elucidated a bit to avoid confusion-while holists typically expend more ontological effort to justify their position and draw on arguments from philosophy of mind, philosophy of biology, or general philosophy of science.

What is the motivation behind ontological foundationalism? Three of the main (and interrelated) reasons for advocating this position are the following.

First, there is a certain realist intuition about theories and explanations in the social sciences, that is, good social theories and explanations simply have to picture or map the existing entities and dependency relations by and large to be explanatory and, hence, are determined in an important sense by the structure of the social world. Therefore, you (allegedly), first, need to have a plausible ontology that tells you something about the general nature of the entities, their properties and causal capacities in a certain domain; only then you can start investigating its details (see Hay 2006 for a similar argument). If there are macroentities sui generis, use theories and explanations referring to these entities, or, if the locus of causality is on the micro level, use microexplanations and so on.

Second, there are deep concerns regarding the epistemic status and the scientific achievements of the social sciences, especially in contrast to the explanatory adequacy (and predictive power) of the natural sciences. In light of these concerns, some philosophers of the social sciences seem to think that 
social scientists would benefit from a firm ontological basis, provided by philosophers, as a starting point for better explanatory practices (e.g., Little 2010, 298f.; see also Epstein 2015b, 7, 40f.).

Third, it might be possible to reduce pluralism in the social sciences via ontological investigations. Many philosophers of the social sciences feel that the current pluralist state of the disciplines, namely, the vast plurality of different theories and forms of explanations in the social sciences, is a deficiency of the social sciences inhibiting the development of the disciplines. There exists no common groundwork allowing for the accumulation of social scientific knowledge. Rather, the social sciences supposedly exist in a state of prenormal science (Kuhn 1970, chapter 2), which means, among other things, that there is no shared research focus but competition between rival schools and explanatory frameworks leading to very different interpretations of the same phenomena. Ontology-based recommendations or restrictions for theories and explanations can be considered the foundationalists' remedy for this situation: ontological foundations might lead to the best or only kind(s) of explanatory frameworks in the social sciences, thereby alleviating pluralism.

Now, there are many arguments against certain forms of doing ontology in the context of the social sciences. For example, many believe that social ontology in the Gilbert-Searle-Tuomela tradition is too self-contained and too isolated from the (theoretical) discourse in the social sciences to be of any real use for the social sciences (e.g., Kincaid 2012). In addition, there has been skepticism toward transferring ontological arguments from philosophy of mind to POSS (Greshoff 2011). However, in the recent literature, a more radical opposition has emerged against the relevance of ontological investigations for the social sciences.

\subsection{Anti-ontological Pragmatism: "Leave Ontology behind!"}

Who supports this more radical opposition and considers ontological projects in POSS in toto as (at least mostly) irrelevant or fruitless for the social sciences? That is, who holds anti-ontological pragmatism?

First of all, this position is widespread among social scientists who focus on empirical research and have a kind of hands-on attitude toward doing social science. Many (though not all) sociologists who exclusively do empirical research share a dismissive attitude toward the relevance of ontological investigations as a foundation for their research (if not all of POSS). This might only be a prevalent prejudice of course. Recently, however, the sociologists Kivinen and Piiroinen $(2006,310)$ develop an actual argument along these lines: 
Rather than revealing the structure of reality or the necessary conditions of scientific inquiries, they [ontological theories about the world] only reveal their holders' a priori metaphysical positions. To pretend that those positions somehow offer necessary groundings for research leads all too often into nothing but vicious circles, into unending battles of intuitions, at the expense of methodologically fruitful debates that might result in improving our social scientific practices.

Instead the authors argue for "concentrating more exclusively on methodological issues, dropping metaphysical conjectures altogether, and replacing them with operationalizable research questions" (Kivinen and Piiroinen 2006, 312).

Kivinen and Piiroinen cite Van Bouwel who has defended a similar (but more moderate) position in POSS. Van Bouwel $(2004,534)$ makes a plea for "giving less weight to metaphysical and ontological debates ... to maximize (our understanding of) good scientific practice." He explicitly questions the foundationalist base assumption in most individualism/holism disputes and states that it should be our explanatory request, rather than ontological assumptions about the social world, that should determine the right level (individualist/holist) of explanation. Following up on this, Van Bouwel and Weber $(2008,439)$ defend a pragmatist deontologized approach to social explanation, which focuses on epistemic interests as a guiding principle for explanatory choice and attempts to "leave the more ontological and conceptual analysis of explanation (with the evidence being our intuitions) behind." The key idea of their approach is to, first, make the explananda and the connected explanation-seeking questions of a certain research endeavor in the social sciences as explicit as possible. In a second step, the thereby determined epistemic interest is used as a standard for choosing the best explanatory framework for this research endeavor.

My final example of the anti-ontological stance is an article with the title The Poverty of Ontological Reasoning. In this article, Tsilipakos $(2012,215)$ argues against the view "that one requires an ontology on which to ground one's methodology and empirical investigations." Tsilipakos is extremely skeptical toward recent attempts to "ontologize" the debates revolving around individualism/holism and different explanatory frameworks in POSS. He even attempts to show, following Wittgenstein, that ontological investigations in POSS are deeply misguided and cannot add anything but confusion to contemporary debates as they misconceive the role of language in ontology (see also Tsilipakos 2015).

What is the motivation behind anti-ontological pragmatism? There seem to be a number of reasons for defending this position. Here, I will only discuss three of the most important ones. 
First, some authors think the prioritization of ontological investigations is slowing down or obstructing real progress in POSS. There are many ontological disputes going on in POSS (e.g., individualism vs. emergentism, naturalism vs. interpretationism, collectivism vs. singularism). These disputes appear to be never-ending - thereby tying up resources - for several reasons. For one thing, some argue, many ontological disputes are just undecidable for epistemic reasons: in many cases, it just seems to be unclear what kind of reason would be sufficient to show that one of the disputants is right. This seems to be so, as philosophers on both sides of a dispute typically agree on the data and the examples used to argue for position A or B. They only disagree about the right ontological theory to describe the data and the examples, and they disagree about the grounds for preferring one ontological theory over the other (see Bennett 2009 for the analogous problem in analytic metaphysics), especially about their metaphysical intuitions (which, sometimes, seem to be the only grounds that are there). In other cases, the putatively deep ontological disputes appear to be nothing more than persistent verbal disputes. The debate revolving around Elder-Vass' concept of relational emergence and his "redescription principle" may be a case in point here (Elder-Vass 2010, 2014; Wahlberg 2014). Thus, the pragmatists argue, we should leave ontology behind and focus on explanatory and methodological issues in the social sciences.

A second reason is the rejection of the realist intuition (see above) concerning theories and explanations. Let's suppose we reach a consensus in ontological matters: according to the pragmatists, sensible social theories and explanation still do not necessarily have to picture the structure of the social world or be derived from ontological premises to be good theories and explanations. It is rather the epistemic interest (what do we want to know?) of the researchers and pragmatic aspects (e.g., efficiency or simplicity) that should guide the choice of explanations and methodological tools.

To use an example by List and Spiekermann $(2013,640)$, the democratic peace hypothesis states that democratic states do not engage in wars against other democratic states. A canonical explanation of this regularity relies on structural macrofeatures of democracies (such as the complexity of decision procedures in democratic states and other institutional constrains). Now, let us assume that ontological individualism is right, that is, democracies are completely determined by individuals, their beliefs, their actions, and so on: why would we-following ontological foundationalism-need additional and extremely complex information about these individual-level details (interactions of politicians, concrete election outcomes, etc.) of the institutional processes within democratic states in this case? The structural explanation on the level of states seems to be quite rigorous (i.e., due to statistical 
control for spurious correlations and confounding variables), it is efficient, and it is illuminating as it provides adequate explanatory information in relation to our epistemic interest (reflected in the research question "Why do democracies not engage in armed conflict with each other although they do fight wars with nondemocratic states?"). If, on the contrary, we wanted to know how democracy $\mathrm{X}$ implemented a certain institutional design (this is a different epistemic interest), the individual-level details would certainly provide essential information. Thus, the anti-ontological pragmatists argue that the main ground for the choice of theories and explanations in the social sciences should be the instrumentality for our epistemic interests - and not ontological reasoning.

Third, and as a consequence of the second point, pragmatists do not see pluralism as a deficiency of the social sciences: we just need different explanatory tools and theoretical perspectives for different research questions and therefore should embrace pluralism as the proliferation of different perspectives on the world instead of striving to eliminate it.

Particularly, the latter two reasons for anti-ontological pragmatism are convincing. They show that ontological foundationalism rests on an "ontological fallacy." It is - for epistemic reasons - just not very persuasive that theories and explanations have to reproduce and are determined by the ontology of the social world. Whether a mechanistic, evolutionary, individualist, or holist explanation is preferable indeed depends on our epistemic interest (what do we want to know?) and pragmatic aspects such as efficiency. The respective type of explanation only has to make a course of social action intelligible (using accepted methodological standards of social research) or "latch on" to some actual pattern in the social world to have the potential to be a successful explanation (see van Fraassen 1980, 39f, for the same point in general philosophy of science). Therefore, pluralism of theories and explanations does not seem to be a bad thing. And this should not be a surprise: the social sciences are not the only disciplines with considerable theoretical and explanatory pluralism. If you look, for example, at the thriving biological sciences and psychology, they appear to be quite pluralist (see Kellert, Longino, and Waters 2006 for more examples of pluralistic sciences). Hence, it seems unclear why explanatory pluralism should be a problem for the social sciences in the first place.

So, what about the first reason then? Do we have to dismiss ontological investigations as they are undecidable and obstructing progress in POSS? Or is there a role to play for ontological investigations in the social sciences after all? The short answer is that it depends on the way of pursuing ontological questions. 


\section{Another Role for Ontology in POSS}

No philosophical ontology of the social sphere determines theories and explanations in the social sciences (nor should it). I agree, and so do many, if not most, social scientists. Hardly anybody in the social sciences seems to be interested in ontological foundations as outlined, and, at least to my knowledge, no social scientist has attempted to ground a new or better social science upon philosophical foundations. This is, of course, in part due to sociological factors such as separated disciplinary discourses, and the sometimes uneasy relationship between philosophers and social scientists. I believe, however, that there is also a reasonable epistemic reason for this situation. In fact, ontological foundationalism appears to be a rather strange position if you look at it from a more general philosophy of science perspective. Why should a philosophical ontology determine scientific research in the first place? Contrast this with any philosophy of the natural sciences: it would be absurd to argue for the analog position in (say) the philosophy of biology or the philosophy of chemistry. So, why is it supposed to be a viable position in POSS?

However, this assessment does not mean that we have to deontologize all of POSS and make a case for an entirely pragmatic methodological approach, which exclusively focuses on different types of explanations and epistemic interests of social scientists (Kivinen and Piiroinen 2006; Van Bouwel and Weber 2008). In fact, ontological investigations of a certain kind can indeed be relevant for the social sciences. I will elucidate and defend this statement in the following section.

The pragmatists' dismissal of ontology as a whole rests on an excessively narrow understanding of what ontological investigations are and what their purpose in the context of the social sciences could be. They (and, likewise, foundationalists) presuppose that ontological reasoning is tantamount to conceptual reasoning, relying mainly on the philosophers' intuitions and preconceptions of reality. As a matter of fact, however, there is a well-established alternative understanding of what ontological investigations can be, namely, the investigation of explicit and implicit ontological assumptions of theories and explanatory frameworks, that is, the investigation of the ontological demands on the world presupposed by scientific theories, models, and related explanatory practices. I want to endorse the view that "a serious study of science must be concerned with what it is that we actually do in scientific work" (Chang 2014, 67, emphasis in the original) and argue for the natural extension of this position (advocated by philosophers of science in practice) to the context of this article. The "practice turn" in philosophy of science (Kendig 
2016; Soler et al. 2014) also offers a fruitful perspective for understanding the place of ontology, and the purpose of doing ontology, in POSS. Understanding ontology in this way would mean a shift from ontological reasoning for the social sciences to ontological investigations of the social sciences, including not only social scientific theories but also their actual application within the disciplines as well as less theory-based explanatory practices. Until now - and somewhat surprisingly - this has only sporadically been done in POSS (see, however, Harold Kincaid's work as an example).

In suggesting that ontological investigations of the social sciences should extend beyond theories, I certainly do not mean to imply that theories are not important. They are an integral part of the social sciences, and theorizing, as well as the application of theories, is itself an epistemic activity (cf. Chang 2014, 67f.). In other words, I take the practice turn not to be a turn away from theory but a turn toward the practical dimension of science, among other things. Please note, that this understanding of ontological reasoning is compatible with my earlier characterization of ontological investigations, as all of the above-mentioned questions can be approached as questions about the ontological assumptions or commitments (broadly construed) of theories, explanatory frameworks, and so on. ${ }^{6}$

There are a number of different roles that ontological investigations understood in this way could play for the social sciences. I will illustrate this with three examples.

1. Ontological investigations do not determine research in the social sciences. However, they can be used to examine and restrict ontological assumptions in light of the postulated explanatory approach.

It is essential that entities used in social explanations have the properties needed to do the explanatory work they are meant to do (see Ludwig 2015 for a very illuminating discussion of the dependence of ontological choices on explanatory interests and scientific practice). If we look at existing social explanations, however, we can see that this is not always the case. For example, the organizational ecologists' answer to the research question of why

\footnotetext{
${ }^{6}$ In the end, my view may also be compatible with the more moderate passages of Van Bouwel's $(2004,534)$ view: “. . . explanatory pluralism will still have to consider ontological issues in order to secure the compatibility and complementarity of theories and explanations" (see also Van Bouwel 2014, 164, fn. 9) - however, he does not really say much about this aspect. In the following section of this article, I attempt to do just this.
} 
certain kinds of organizations survive better in different kinds of environments cites different organizational strategies as well as Darwinian selection mechanisms on the population level as important explanatory factors (Hannan and Freeman 1977, 1989). Reydon and Scholz (2009) criticize ecological explanations of this kind from an ontological point of view. According to them, the organizational ecologists' approach de facto lacks an evolutionary mechanism. The reason is that it specifies entities ("organizational populations") that are not capable of evolving in a Darwinian sense. In other words, the explanatory core of this Darwinian research approach seems to be flawed as the relevant entities cannot fulfill the intended explanatory role for ontological reasons.

In cases like this, ontological investigations in POSS have a normative function as they not only examine and clarify but also critically evaluate the ontological assumptions of social explanations in light of their explanatory function. The idea, then, is not to generally exclude explanatory frameworks for a priori ontological reasons (e.g., the hermeneutic nature of human action), as that would be ontological foundationalism all over again, but to provide a contextual critique of ontological assumptions given the postulated explanatory approach and the epistemic goals of the research enterprise. ${ }^{7}$ This kind of ontological investigation is relevant for the social sciences as it is in close contact with explanatory practices and has the potential to advance the social sciences through accompanying critique.

2. Some forms of social explanations rely heavily on unclear or takenfor-granted ontological assumptions that can (and should) be made clear/explicit by ontological investigations.

The social mechanism approach will be used to illustrate this point. The general idea of mechanistic explanations in the social sciences is to "open up the black box." Mechanistic explanations explain certain social phenomena by describing their generative mechanism, that is, the entities (often individuals) and causal processes that, given a specific arrangement of the entities and a certain context, produce the phenomena in question (Hedström and Swedberg 1996; Hedström and Ylikoski 2010). Naturally, mechanistic explanations can be useful for many epistemic interests.

Mechanistic approaches are heavily infused with ontological assumptions because they think that a (idealized) description of the actual mechanism in the real world ipso facto is an explanation of the phenomenon it produces.

${ }^{7}$ Many thanks to Thomas Reydon for helping me realize what I actually wanted to say here. 
Having said this, there appears to be quite a lot of ontological mopping-up work to do for philosophers of the social sciences. Here are two examples:

a. In some cases, it is not very clear what kinds of relations are supposed to exist between the entities in a social mechanism. At times, causal, intentional, constitutive, and spaciotemporal relations, as well as relations "via social actions," are lumped together (often as arrows in a diagram), leaving a central part of the described mechanism sketchy or ill-defined (see, however, Little's 2012, 147, initial approach as a useful starting point for spelling out different mechanistic relations in more detail). It would, therefore, seem worthwhile to take a closer look at concrete examples of mechanistic explanations (not only methodological texts about these explanations), to analyze the actual ontological assumptions of the explanations in question, and to compare different mechanist explanations in this respect. (This could also be a contribution to a taxonomy of different kinds of social mechanisms.)

Above all, it is not always clear how many levels of entities are supposed to exist and how the different levels of social reality relate to each other in the description of a social mechanism. In what way do macroentities such as organizations depend on individuals? Are there genuine causal relations between macroentities and microentities (individual agents) in mechanistic explanation X? Coleman's (1990) famous micro-macro model ("Coleman's boat"), for example, seems to contain an ambiguity in relation to the question of whether there exists genuine downward causation or only as-if downward causation or some kind or other (structural?) kind of determination relation between macro- and micro level (Udehn 2001, 295ff.). ${ }^{8}$ Whichever option one endorses, it would be illuminating to really understand how these downward relations are meant to be made intelligible in mechanistic explanations, with macroentities typically being conceived as composed of the entities on the lower level (individuals).

Answers to these questions would make descriptions of social mechanisms more explicit and thereby the respective mechanistic explanation more intelligible. As a side note, how these questions are answered is far from inconsequential from a practical point of view, because these topics are highly relevant for social practices informed by the social sciences: it just makes a difference whether social workers, politicians, or business managers

\footnotetext{
${ }^{8}$ Following Hedström and Ylikoski (2010), I think that Coleman can indeed be seen as an example of a mechanistic approach in sociology.
} 
think there exists genuine structural or downward causation (say) in organizations - or not. The sense making of social situations depends on the interpretative resources of the involved agents. These interpretative resources in turn are influenced by social scientific theories and explanations (Hacking 1995). Hence, ontological assumptions influence, at least to some degree, our sense making in social situations and, as a consequence, our actions.

b. The second example for ontological mopping-up work is related to the former aspect: it is widely held (though not by everybody in the mechanist camp) that social mechanistic explanations are ipso facto microfoundationalist. The now classic article on mechanistic explanations by Machamer, Darden, and Craver (2000), however, is much more liberal in this respect in that it states that higher level entities are an essential explanatory part of mechanistic explanations. They are not just "shortcuts" or "context" but are at the core of multilevel explanations. Why then is it the case that many social mechanists seem to think that the core of a social mechanism has to be spelled out in terms of interacting individuals whenever possible? Does this imply the existence of unreflected-upon foundationalist assumptions concerning social mechanisms? Could these inhibit social research as certain kinds of (possibly) explanatory macromechanisms disappear from view due to taken-for-granted ontological assumptions (cf. Kaidesoja 2013)?

One can, of course, choose not to think about these ontological issues, but the fact that one is not interested in the ontological aspects of the investigation does not mean that these aspects are not there; they just remain unexamined and, in many cases, unclear. Given the strong ontological flavor of mechanistic explanations, it seems inevitable to engage in these ontological issuesnot as a foundation of mechanistic explanations but as constructive and critical complement. Furthermore, the analysis of the ontological assumptions of (say) mechanistic explanations would make it possible to reveal the ways in which they guide research practices in the social sciences. ${ }^{9}$ What kinds of phenomena or activity patterns are (not) likely to become visible within a certain ontological framework? What are the differences between different ontological frameworks in this respect?

In cases like these - (a) and (b) - ontological investigations in POSS primarily have a descriptive and clarificatory function. What kinds of relations and levels are assumed to exist? How are they related? What are the

${ }^{9}$ I owe this point to Brad Wray. 
consequences of certain ontological assumptions? This seems to be a useful project in itself in that it helps to elucidate certain types of social explanations. However, in some cases, ontological investigations of this kind may also have a normative component, namely, whenever the philosophical (re) description or clarification reveals inconsistencies in the ontological framework under consideration. In these cases, the purely descriptive approach might shift into the mode of "revisionary metaphysics." This means reflecting on the question of what the relevant ontological assumptions should be in the respective explanatory framework. (This may sometimes turn into the contextual critique of the ontological assumptions in question, see above (1).) I think it is obvious that this kind of embedded critique has the potential to be highly useful for social scientific practice.

3. The critical analysis and comparison of different conceptions of "the social" can illuminate deeper relationships between different explanatory frameworks and may thereby contribute to a clarifying systematization of the fragmented social sciences.

As stated above, pluralism is not a deficiency of the social sciences. However, pluralism and fragmentation are not the same thing; and the social sciences indeed appear to be fragmented in different respects (Tang 2011), leading to a kind of pseudopluralism without much substantial interparadigmatic discourse or knowledge integration. One (though not the only one) of the major reasons for this situation is this. There exist many seemingly incompatible, or at least very different, conceptions of the central subject matter of the social sciences, that is, "the social," roughly pointing to such diverse things as wedding customs, gender roles, churches, bureaucracies, states, World War II, and the occidental modernization. There is no agreement concerning the intension or extension of these subconcepts across different paradigms or schools. Furthermore, there is no agreedupon classification of social phenomena, say in institutions and organizations or in different types of social systems. The term institution, for example, is used interchangeably with "social structure" by some social scientists, whereas sometimes it is used to denote patterns of behavior or whole systems of rules and practices (see Miller 2012 for some variants). This seems to be one of the reasons why social scientists using the same words are occasionally talking past each other. The two main reactions to this situation are (a) indifference and (b) attempts to synthesize very different conceptions of "the social" into one comprehensive conception (the classic example being Talcott Parsons; for recent integration attempts, see, for example, Elder-Vass 2007; Esser 1993). 
I am quite skeptical toward the synthetic approach, however, as all attempts of paradigm integration until now have failed. So far, there is no widely accepted comprehensive paradigm (i.e., explanatory framework), and this is no accident. Attempts to synthesize different conceptions of "the social" underestimate the differences between these conceptions in the social sciences and tend toward imperialistic assimilation instead of true integration. In addition, these attempts are premature, as we lack a deeper understanding of the actual ontological assumptions of different explanatory frameworks, and the deeper similarities, complementarities, and incommensurabilities between them. At present, I think we do not know whether different paradigms in the social sciences (e.g., Bourdieu's Practice Theory, Luhmann's Systems Theory) really have deep or even incommensurable ontological differences or whether they just highlight different aspects of the social, as Tang (2011) would suggest. It may turn out to be the case that many concepts of the social - apparently carving social reality at different jointsare, in the end, compatible, as the perceived differences are only shallow.

To be sure, you can already find some framework comparisons in the social science literature, but, for the most part, these comparisons rely mainly on the (meta-)theoretical texts of the respective paradigms or school founders (see, for example, López and Scott 2000). However, these "grounding texts" tend to overemphasize differences between different concepts of the social. A comparison based on these texts risks buying into these overstatements. For this reason, a philosopher of the social sciences interested in comparing different conceptions of the social should not only rely on the (meta-)theoretical texts. She should also look for potential case studies in which an explanation of a given social phenomenon or regularity is attempted within a certain explanatory framework. In a second step, she would analyze the implicit ontological assumptions made by the framework in this case and critically compare these with the explicitly stated assumptions to arrive at a somehow adjusted picture of the ontological assumptions of the framework in question. After having done this with different frameworks, she would have a better idea of the actual ontological assumptions of these frameworks and, therefore, would have a more reliable starting point for comparison between different paradigms.

In this case, ontological investigations in POSS primarily have a clarificatory and systematizing function. What are the actual ontological demands on the world of different paradigms? Do they really differ that much in explanatory practice or are the supposedly deep differences only apparent? What are core differences and similarities? Critical and impartial investigations of the actual ontological assumptions regarding "the social" (conducted by philosophers of the social sciences) could provide a partial remedy 
to the fragmentation of the social sciences and help us to understand how many different ontological playing pieces are really there. It may even be possible to create a kind of meta-framework for different core conceptions of the social that would enable meaningful comparison and could foster interparadigmatic discourse and a fruitful kind of pluralism instead of talking at cross-purposes. This would not only be interesting from a philosophical point of view but - again — would be useful for social scientists as well.

There is even some concrete evidence that a project like this would be welcomed by social scientists. A group of prominent German sociologist recently published a working paper that made a similar case for the need of an impartial meta-framework for theory comparison and hinted at the possibility to base this framework on different core conceptions of "the social" (Greshoff, Lindemann, and Schimank 2007). This very much looks like a job to which philosophers of the social sciences could — and should — contribute.

\section{Conclusion}

In this article, I attempted to show that ontological foundationalism as well as anti-ontological pragmatism are unsatisfactory: ontology is neither the foundation for the extension of social scientific knowledge and explanatory strategies, nor are ontological questions irrelevant for the social sciences and social explanations. Rather, there are a number of different functions that ontological investigations in line with a philosophy of social science in practice perspective can have for the social sciences, namely, (a) the critical examination and restriction of ontological assumptions in light of the postulated explanatory approach, (b) the clarification of ontological assumptions in explanations, and (c) the illumination of relationships between different explanatory frameworks in the social sciences. Ontological investigations in these cases are deeply linked to epistemological issues in POSS and certainly can contribute to the advancement of the social sciences. Accordingly, I want to end this article with a plea for more integration of explanatory and methodological work with ontological investigations in POSS - instead of doing either/or.

\section{Acknowledgments}

I would like to thank two anonymous reviewers, Jeroen Van Bouwel (Ghent), Paul Hoyningen-Huene (Zurich/ Hannover), Nicolas Wüthrich (London), audiences at the Conference of the European Network for the Philosophy of the Social Sciences (ENPOSS) 2014 and the Congress on Logic, Methodology, and Philosophy of Science (CLMPS) 2015, as well as the participants of the research seminar in philosophy (Summer 2015) at the Leibniz Universität Hannover for helpful comments on earlier versions of this article. Special thanks to Lucie White (Hannover) for correcting and improving my English. 


\section{Declaration of Conflicting Interests}

The author(s) declared no potential conflicts of interest with respect to the research, authorship, and/or publication of this article.

\section{Funding}

The author(s) received no financial support for the research, authorship, and/or publication of this article.

\section{References}

Baert, Patrick. 2005. Philosophy of the Social Sciences: Towards Pragmatism. Cambridge: Polity Press.

Bennett, Karen. 2009. "Composition, Colocation, and Metaontology." In Metametaphysics: New Essays on the Foundations of Ontology, edited by David John Chalmers, David Manley, and Ryan Wasserman, 38-76. Oxford: Oxford University Press.

Chang, Hasok. 2014. "Epistemic Activities and Systems of Practice: Units of Analysis in Philosophy of Science after the Practice Turn." In Science after the Practice Turn in the Philosophy, History, and Social Studies of Science, edited by Léna Soler, Sjoerd Zwart, Michael Lynch, and Vincent Israel-Jost, 67-79. London: Routledge.

Coleman, James S. 1990. Foundations of Social Theory. Cambridge: Belknap Press.

Davis, John B. 2006. "The Turn in Economics: Neoclassical Dominance to Mainstream Pluralism?" Journal of Institutional Economics 2 (1): 1-20. doi:10.1017/ S1744137405000263.

Debreu, Gerard. 1991. "The Mathematization of Economic Theory." The American Economic Review 81 (1): 1-7.

Demeulenaere, Pierre. 2011. "Introduction." In Analytical Sociology and Social Mechanisms, edited by Pierre Demeulenaere, 1-32. Cambridge: Cambridge University Press.

Durkheim, Emile. (1895) 1964. The Rules of Sociological Method. New York: Free Press.

Elder-Vass, Dave. 2007. "Reconciling Archer and Bourdieu in an Emergentist Theory of Action." Sociological Theory 25 (4): 325-46. doi:10.1111/j.14679558.2007.00312.x.

Elder-Vass, Dave. 2010. The Causal Power of Social Structures: Emergence, Structure and Agency. Cambridge: Cambridge University Press.

Elder-Vass, Dave. 2014. "Redescription, Reduction, and Emergence: A Response to Tobias Hansson Wahlberg." Philosophy of the Social Sciences 44 (6): 792-7. doi:10.1177/0048393113515386.

Epstein, Brian. 2015a. “A Framework for Social Ontology.” Philosophy of the Social Sciences 46:147-67. doi:10.1177/0048393115613494.

Epstein, Brian. 2015b. The Ant Trap: Rebuilding the Foundations of the Social Sciences. New York: Oxford University Press. 
Esser, Hartmut. 1993. Soziologie: Allgemeine Grundlagen. Frankfurt am Main: Campus.

Friedman, Milton. (1953) 2008. "The Methodology of Positive Economics." In The Philosophy of Economics: An Anthology, edited by Daniel M. Hausman, 3rd ed., 145-78. Cambridge: Cambridge University Press.

Greshoff, Rainer. 2011. "Emergenz und Reduktion in sozialwissenschaftlicher Perspektive." In Emergenz: Zur Analyse und Erklärung komplexer Strukturen, edited by Jens Greve and Annette Schnabel, 214-52. Frankfurt am Main: Suhrkamp.

Greshoff, Rainer, Gesa Lindemann, and Uwe Schimank. 2007. "Theorienvergleich und Theorienintegration-Disziplingeschichtliche und methodische Überlegungen zur Entwicklung eines paradigmenvermittelnden conceptual framework für die Soziologie.” Arbeitsgruppe Soziologische Theorie (AST)/Universität Oldenburg, Diskussionspapiere. http://www.ssoar.info/ssoar/handle/document/19777.

Guala, Francesco. 2007. "The Philosophy of Social Science: Metaphysical and Empirical." Philosophy Compass 2 (6): 954-80. doi:10.1111/j.17479991.2007.00095.x.

Hacking, Ian. 1995. "The Looping Effects of Human Kinds." In Causal Cognition: A Multidisciplinary Approach, edited by Dan Sperber, David Premack, and Ann James Premack, 351-383. Cambridge: Harvard University Press.

Hannan, Michael T., and John Freeman. 1977. "The Population Ecology of Organizations.” American Journal of Sociology 82 (5): 929-64.

Hannan, Michael T., and John Freeman. 1989. Organizational Ecology. Cambridge: Harvard University Press.

Hausman, Daniel M., ed. 2008. The Philosophy of Economics: An Anthology. 3rd ed. New York: Cambridge University Press.

Hay, Colin. 2006. "Political Ontology." In The Oxford Handbook of Contextual Political Analysis, edited by Robert E. Goodin and Charles Tilly, 78-96. Oxford: Oxford University Press.

Hedström, Peter, and Richard Swedberg. 1996. "Social Mechanisms." Acta Sociologica 39 (3): 281-308.

Hedström, Peter, and Petri Ylikoski. 2010. "Causal Mechanisms in the Social Sciences." Annual Review of Sociology 36 (1): 49-67. doi:10.1146/annurev. soc.012809.102632.

Hoyningen-Huene, Paul, and Simon Lohse. 2015. "Kuhn, Thomas S. (1922-96).” In International Encyclopedia of the Social \& Behavioral Sciences, edited by James D. Wright, 2nd ed., vol. 13, 133-38. Oxford: Elsevier.

Kaidesoja, Tuukka. 2013. "Overcoming the Biases of Microfoundationalism: Social Mechanisms and Collective Agents." Philosophy of the Social Sciences 43 (3): 301-22. doi:10.1177/0048393113488872.

Kellert, Stephen H., Helen E. Longino, and C. Kennteh Waters, eds. 2006. Scientific Pluralism (Minnesota Studies in the Philosophy of Science). Minneapolis: University of Minnesota Press.

Kendig, Catherine, ed. 2016. Natural Kinds and Classification in Scientific Practice. London: Routledge. 
Kincaid, Harold. 2012. "How Should Philosophy of Social Science Proceed?" Metascience 21 (2): 391-94. doi:10.1007/s11016-011-9592-7.

Kivinen, Osmo, and Tero Piiroinen. 2006. "Toward Pragmatist Methodological Relationalism: From Philosophizing Sociology to Sociologizing Philosophy." Philosophy of the Social Sciences 36(3): 303-29. doi:10.1177/0048393106289794. Kivinen, Osmo, and Tero Piiroinen. 2007. "Sociologizing Metaphysics and Mind: A Pragmatist Point of View on the Methodology of the Social Sciences." Human Studies 30 (2): 97-114. doi:10.1007/s10746-007-9049-6.

Kuhn, Thomas S. 1970. The Structure of Scientific Revolutions. 2nd ed. Chicago: University of Chicago Press.

Ladyman, James, Don Ross, David Spurrett, and John G. Collier. 2007. Every Thing Must Go: Metaphysics Naturalized. Oxford: Oxford University Press.

List, Christian, and Kai Spiekermann. 2013. "Methodological Individualism and Holism in Political Science: A Reconciliation." American Political Science Review 107 (4): 629-43. doi:10.1017/S0003055413000373.

Little, Daniel. 1998. Microfoundations, Method, and Causation: On the Philosophy of the Social Sciences. New Brunswick: Transaction.

Little, Daniel. 2009. "The Heterogeneous Social: New Thinking about the Foundations of the Social Sciences." In Philosophy of the Social Sciences: Philosophical Theory and Scientific Practice, edited by Chrysostomos Mantzavinos, 154-78. Cambridge: Cambridge University Press.

Little, Daniel. 2010. "Philosophy of Sociology." In Philosophies of the Sciences, edited by Fritz Allhoff, 293-323. Oxford: Wiley-Blackwell.

Little, Daniel. 2012. "Explanatory Autonomy and Coleman's Boat." Theoria 27 (2): 137-51.

Little, Daniel. 2014. "Actor-Centered Sociology and the New Pragmatism." In Rethinking the Individualism-Holism Debate, edited by Julie Zahle and Finn Collin, 55-75. Cham: Springer International Switzerland.

López, José, and John Scott. 2000. Social Structure: Concepts in the Social Sciences. Buckingham: Open University Press.

Ludwig, David. 2015. "Ontological Choices and the Value-Free Ideal.” Erkenntnis. Published electronically. doi:10.1007/s10670-015-9793-3.

Machamer, Peter, Lindley Darden, and Carl F. Craver. 2000. "Thinking about Mechanisms." Philosophy of Science 67 (1): 1-25.

Mantzavinos, Chrysostomos, ed. 2009. Philosophy of the Social Sciences: Philosophical Theory and Scientific Practice. Cambridge: Cambridge University Press.

Miller, Seumas. 2012. "Social Institutions." In The Stanford Encyclopedia of Philosophy, edited by Edward N. Zalta, Fall 2012 ed. http://www.science.uva. $\mathrm{nl} / \sim$ seop/entries/social-institutions/.

Reiss, Julian. 2013. Philosophy of Economics: A Contemporary Introduction (Routledge Contemporary Introductions to Philosophy). New York: Routledge.

Reydon, Thomas A. C., and Markus Scholz. 2009. "Why Organizational Ecology Is Not a Darwinian Research Program.” Philosophy of the Social Sciences 39 (3): 408-39. doi:10.1177/0048393108325331. 
Sawyer, R. Keith. 2002. "Nonreductive Individualism Part I-Supervenience and Wild Disjunction." Philosophy of the Social Sciences 32 (4): 537-59.

Sawyer, R. Keith. 2003. "Nonreductive Individualism Part II-Social Causation." Philosophy of the Social Sciences 33 (2): 203-24.

Sawyer, R. Keith. 2005. Social Emergence. Societies as Complex Systems. Cambridge: Cambridge University Press.

Searle, John R. 1995. The Construction of Social Reality. New York: Free Press.

Searle, John R. 2008. "Language and Social Ontology." Theory and Society 37 (5): 443-59. doi:10.1007/s11186-008-9068-y.

Searle, John R. 2010. Making the Social World: The Structure of Human Civilization. Oxford: Oxford University Press.

Soler, Léna, Sjoerd Zwart, Michael Lynch, and Vincent Israel-Jost, eds. 2014. Science after the Practice Turn in the Philosophy, History, and Social Studies of Science. London: Routledge.

Tang, Shiping. 2011. "Foundational Paradigms of Social Sciences." Philosophy of the Social Sciences 41 (2): 211-49. doi:10.1177/0048393109355294.

Tsilipakos, Leonidas. 2012. "The Poverty of Ontological Reasoning." Journal for the Theory of Social Behaviour 42 (2): 201-19.

Tsilipakos, Leonidas. 2015. "Realist Social Theory and Its Losing Battle with Concepts." Philosophy of the Social Sciences 45 (1): 26-52. doi:10.1177/0048393114525859.

Udehn, Lars. 2001. Methodological Individualism: Background, History, and Meaning. London: Routledge.

Van Bouwel, Jeroen. 2004. "Individualism and Holism, Reduction and Pluralism: A Comment on Keith Sawyer and Julie Zahle." Philosophy of the Social Sciences 34 (4): 527-35. doi:10.1177/0048393104269198.

Van Bouwel, Jeroen. 2014. "Explanatory Strategies Beyond the Individualism/ Holism Debate." In Rethinking the Individualism-Holism Debate. Essays in the Philosophy of Social Science, edited by Julie Zahle and Finn Collin, 153-76. Cham: Springer International Switzerland.

Van Bouwel, Jeroen, and Erik Weber. 2008. "De-ontologizing the Debate on Social Explanations: A Pragmatic Approach Based on Epistemic Interests." Human Studies 31 (4): 423-42. doi:10.1007/s10746-008-9102-0.

Van Fraassen, Bas. C. 1980. The Scientific Image. Oxford, New York: Clarendon Press.

Wahlberg, Tobias Hansson. 2014. "Elder-Vass on the Causal Power of Social Structures." Philosophy of the Social Sciences 44 (6): 774-91. doi:10.1177/0048393113500213.

Watkins, J. W. N. 1952. "Ideal Types and Historical Explanation.” The British Journal for the Philosophy of Science 3 (9): 22-43.

Watkins, J. W. N. 1957. "Historical Explanation in the Social Sciences." The British Journal for the Philosophy of Science 8 (30): 104-17.

Zahle, Julie. 2003. "The Individualism-Holism Debate on Intertheoretic Reduction and the Argument from Multiple Realization." Philosophy of the Social Sciences 33 (1): 77-99. 
Zahle, Julie, and Finn Collin, eds. 2014. Rethinking the Individualism-Holism Debate: Essays in the Philosophy of Social Science. Cham: Springer International Switzerland.

\section{Author Biography}

Simon Lohse is a research fellow at the Institute of Philosophy and the Centre for Ethics and Law in the Life Sciences at Leibniz Universität Hannover. His research interests are in philosophy of the social sciences, general philosophy of science, and topics at the junction of philosophy of science, bioethics, and science studies. 